\title{
Pilarisasi Lempung dengan Al/Cr sebagai Adsorben Minyak Sisa Pakai
}

Tiska Eva Triandhani ${ }^{1}$, Taslimah ${ }^{1}$, Sriyanti ${ }^{*}$

${ }^{1}$ Departemen Kimia, Fakultas Sains dan Matematika, Universitas Diponegoro

*Corresponding author: sriyanti@live.undip.ac.id

\begin{abstract}
Abstrak
Minyak goreng yang digunakan berulang kali mengakibatkan kerusakan minyak dan membahayakan pemakainya. Salah satu solusi untuk menanganinya ialah dengan metode adsorpsi. Lempung terpilar $\mathrm{Al} / \mathrm{Cr}$ telah dibuat sebagai adsorben minyak sisa pakai. Penelitian ini bertujuan untuk menentukan suhu optimum kalsinasi pada pemilaran lempung dengan $\mathrm{Al} / \mathrm{Cr}$ dan menentukan kualitas minyak sisa pakai berdasarkan bilangan asam dan bilangan peroksida. Karakterisasi lempung terpilar menggunakan X-Ray Diffraction (XRD). Selanjutnya daya adsorpsi lempung terpilar terhadap minyak sisa pakai diukur menggunakan Spektrofotometer UV-Vis. Uji kualitas minyak dilakukan berdasarkan penentuan bilangan asam dan bilangan peroksida sesuai syarat mutu minyak goreng yaitu SNI 01-3741-2013. Hasil penelitian menunjukkan bahwa, pemilaran lempung $\mathrm{Al} / \mathrm{Cr}$ dapat meningkatkan basal spacing. Lempung terpilar $\mathrm{Al} / \mathrm{Cr}$ dengan suhu kalsinasi $400^{\circ} \mathrm{C}$ memiliki basal spacing terbesar yaitu fraksi ringan $18,84 \AA$ dan fraksi berat 16,53 Å. Kemampuan lempung terpilar Al/Cr untuk adsorpsi minyak sisa pakai memiliki daya serap besar pada suhu kalsinasi $400^{\circ} \mathrm{C}$ yaitu pada fraksi berat 9,16 \% dan fraksi ringan 6,28 \%. Lempung terpilar $\mathrm{Al} / \mathrm{Cr}$ mampu menurunkan bilangan asam dan bilangan peroksida, bahwa semakin lama waktu kontak adsorpsi bilangan asam dan bilangan peroksida semakin menurun.
\end{abstract}

Kata Kunci: Lempung terpilar Al/Cr, minyak sisa pakai, bilangan asam, bilangan peroksida

\section{Pendahuluan}

Tingginya harga minyak goreng bagi sebagian masyarakat menengah ke bawah dan kurangnya pengetahuan membuat masyarakat sering kali menggunakan minyak goreng yang telah dipakai hingga berulang kali. Penggunaan minyak goreng berulang kali akan mengakibatkan kerusakan minyak. Kerusakan utama pada minyak adalah ditandai bau tengik dan perubahan warna minyak menjadi lebih gelap. Jenis kerusakan yang lain adalah peningkatan asam lemak bebas (FFA) dan angka peroksida (PV)[1]. Untuk menekan pengaruh pemakaian minyak jelantah, perlu diupayakan pengolahan (regenerasi) minyak goreng sisa pakai. Regenerasi minyak bertujuan untuk memperbaiki kualitas minyak goreng sisa pakai. Regenerasi dapat dilakukan dengan cara adsorpsi [2].

Lempung bersifat sebagai adsorben. Salah satu penggunaannya adalah untuk pemucatan minyak sawit atau minyak kedelai [3]. Lempung juga dapat menurunkan absorbansi pada pemucatan minyak [4]. Untuk meningkatkan kemampuan kerjanya, biasanya lempung sebelum digunakan dimodifikasi terlebih dahulu agar lebih efektif[5]. Salah satu cara memodifikasi lempung adalah dengan pilarisasi. Jika lempung dimodifikasi menjadi lempung terpilar, maka ia memiliki pori-pori yang lebih besar. Adanya sifat unggul dari lempung terpilar tersebut menjadikan material tersebut potensial untuk digunakan sebagai adsorben[6].

Menurut Ding dkk.[7] tentang pemilaran lempung $\mathrm{Al} / \mathrm{Cr}$ menunjukkan bahwa luas permukaan spesifik, volume pori, dan jarak antar-lapisan jauh lebih besar. Sedangkan pemilaran Cr-Bentonit dapat menurunkan angka peroksida dan angka asam .

\section{Metode Penelitian}

Penelitian dilakukan melalui beberapa tahap meliputi preparasi lempung alam, aktivasi lempung, tahap pemilaran lempung. Karakterisasi lempung terpilar menggunakan $X$ Ray Diffraction (XRD). Selanjutnya tahap adsorpsi minyak sisa pakai, kemampuan adsorpsi ditentukan Spektrofotometer UV-Vis, lalu dilanjutkan untuk uji kualitas minyak yaitu penentuan bilangan asam dan bilangan 
peroksida. Penelitian dilakukan di Laboratorium Kimia Anorganik Fakultas Sains dan Matematika Universitas Diponegoro.

\subsection{Alat dan Bahan}

Alat yang digunakan dalam penelitian adalah set peralatan gelas, magnetic stirrer, kertas wattmen, furnace, vakum, penggerus, ayakan 170 mesh, corong kaca, $\mathrm{pH}$ meter, corong buncher, kaca arloji, oven, timbangan, pipet tetes, pengaduk, alumunium foil, spektrofotometer UV-Vis (Shimadzu), X-Ray Diffraction/XRD (bruker D).

Bahan yang digunakan dalam penelitian adalah lempung alam yang diambil di daerah bayat Boyolali, akuades, $\mathrm{HCl} 2 \mathrm{M}, \mathrm{AgNO}_{3}$, $\mathrm{CrCl}_{3} .6 \mathrm{H}_{2} \mathrm{O}$ (pa), $\mathrm{AlCl}_{3} .6 \mathrm{H}_{2} \mathrm{O}(\mathrm{pa})$, minyak sisa pakai (jelantah), asam asetat glasial (pa), kloroform, larutan kalium iodida jenuh, natrium thiosulfat $0,01 \mathrm{~N}$, etanol 95\% netral, indikator $\mathrm{pp}$ $1 \%, \mathrm{NaOH}(\mathrm{pa}), \mathrm{HCl}$ pekat (pa), asam oksalat, larutan kanji 1\%, kalium dikromat.

\subsection{Cara Kerja}

\subsubsection{Preparasi Lempung Alam}

Lempung yang didapatkan dari Bayat Boyolali dibersihkan dengan air. Kemudian dilakukan proses fraksinasi untuk memisahakan fraksi ringan dan fraksi berat. Proses fraksinansi dilakukan dengan cara mencampurkan lempung yang telah bersih dengan aquades. Fraksi ringan yang didapat kemudian dipisahkan dan dikeringkan pada suhu $110^{\circ} \mathrm{C}$ selama 2 jam. Selanjutnya fraksi ringan digerus dan kemudian diayak dengan ayakan 170 mesh. Perlakuan yang sama terhadap fraksi berat.

\subsubsection{Aktivasi Lempung}

Fraksi ringan dan fraksi berat lolos ayakan 170 mesh masing-masing sebanyak $100 \mathrm{~g}$ diaktivasi dengan menggunakan larutan $\mathrm{HCl} 2 \mathrm{M}$ diaduk menggunakan pengaduk magnetitk selama 10 menit kemudian didiamkan selama 24 jam. Sampel disaring menggunakan kertas saring whattmen, selanjutnya kemudian dicuci dengan aquades hingga mencapai $\mathrm{pH}$ aquades. Selanjutnya sampel dikeringkan pada suhu $110^{\circ} \mathrm{C}$ selama 2 jam. Setelah didapatkan lempung yang telah kering kemudian dilakukan penggerusan dan pengayakan dengan ayakan 170 mesh dan di karakerisasi dengan XRD.

\subsubsection{Pemilaran Lempung}

Sebanyak 50 gram masing-masing fraksi ringan dan fraksi berat yang telah diaktivasi kemudian dicampurkan dengan $500 \mathrm{~mL}$ aquades diaduk menggunakan magnetic stirrer selama 24 jam pada temperatur kamar.

Pembuatan larutan pemilar $\mathrm{CrCl}_{3} \cdot 6 \mathrm{H}_{2} \mathrm{O}$ dan $\mathrm{AlCl}_{3} .6 \mathrm{H}_{2} \mathrm{O}$ yang digunakan adalah konsentrasi 0,1 $\mathrm{mol} / \mathrm{L}$ dan larutan $\mathrm{NaOH} \mathrm{0,2} \mathrm{mol} / \mathrm{L}$. Penambahan $\mathrm{NaOH}$ ke dalam larutan $\mathrm{CrCl}_{3} .6 \mathrm{H}_{2} \mathrm{O}$ dan $\mathrm{AlCl}_{3} \cdot 6 \mathrm{H}_{2} \mathrm{O}$ dilakukan secara perlahan. Selanjutnya agen pemilar ditambahkan ke dalam suspensi lempung dengan perbandingan agen pilar Al 25\% dan Cr 75\% diaduk menggunakan magnetic stirrer selama 24 jam.

Agen pemilar ditambahkan ke dalam suspensi lempung fraksi ringan dan fraksi berat dan diaduk menggunakan magnetic stirrer selama 24 jam pada temperatur kamar. Hasil dari interkalasi disaring, dicuci dengan aquades dan dikeringkan dalam oven pada temperatur $110^{\circ} \mathrm{C}$ selama 2 jam. Kemudian dilakukan variasi kalsinasi pada temperatur $300^{\circ} \mathrm{C}, 350^{\circ} \mathrm{C}, 400^{\circ} \mathrm{C}$ dengan laju kenaikan temperatur $5^{\circ} \mathrm{C} /$ menit. Selanjutnya hasil lempung terpilar $\mathrm{Al} / \mathrm{Cr}$ dikarakterisasi dengan $X$ Ray Diffraction (XRD).

\subsubsection{Adsorpsi Minyak Sisa Pakai}

Adsorpsi minyak sisa pakai dibuat dengan perbandingan adsorben : adsorbat sebesar $2 \%$ yaitu 0,2 gram : $10 \mathrm{~mL}$. Proses adsorpsi dilakukan dengan waktu kontak adsorpsi 15 menit pada suhu hangat $\left(40^{\circ} \mathrm{C}\right)$. kemudian disaring menggunakan kertas saring, sehingga diperoleh filtrat. Pengulangan yang sama untuk tiap suhu kalsinasi $300^{\circ} \mathrm{C}, 350^{\circ} \mathrm{C}$ dan $400^{\circ} \mathrm{C}$. Filtrat yang telah didapatkan, diencerkan terlebih dahulu. Pengenceran filtrat minyak sisa pakai (filtrat) dilakukan dengan kloroform dengan mengambil minyak sisa pakai $2 \mathrm{~mL}$ ke dalam $10 \mathrm{~mL}$ labu ukur dianalisis dengan spektrofotometer UV-Vis pada panjang gelombang maksimum untuk menentukan suhu optimum.

\subsubsection{Penentuan Bilangan Peroksida (SNI 01- 3741-2013)}

Minyak sebanyak 2 gram dimasukkan ke dalam erlenmeyer serta ditambahkan $20 \mathrm{~mL}$ pelarut asam asetat glasial : kloroform (3:2), diaduk hingga larutan homogen. Setelah larutan homogen ditambahkan 0,5 mL larutan $\mathrm{KI}$ jenuh dan ditutup rapat sambil dikocok. Selanjutnya ditambahkan $20 \mathrm{~mL}$ akuades. Campuran tersebut kemudian dititrasi dengan larutan $\mathrm{Na}_{2} \mathrm{~S}_{2} \mathrm{O}_{3}$ yang telah distandarisasi sampai warna kuning hampir hilang. Kemudian ditambah 0,5 $\mathrm{mL}$ indikator amilum $1 \%$. Titrasi dilanjutkan sampai titik ekivalen yaitu tepat saat warna biru hilang. Volum titran dicatat. Dengan cara yang sama dibuat juga titrasi larutan blangko. 


\subsubsection{Penentuan Bilangan Asam (SNI 01-3741- 2013)}

Sebanyak 2 gram minyak sisa pakai di dalam erlenmeyer $100 \mathrm{~mL}$ diambah $10 \mathrm{~mL}$ etanol 95\%, kemudian dipanaskan menggunakan kompor listrik selama 30 menit sambil diaduk. Larutan didinginkan, kemudian ditambahkan indikator fenolftalein sebanyak 3 tetes. Larutan dititrasi dengan $\mathrm{NaOH}$ 0,1 N yang telah di standarisasi hingga berwarna merah jambu minimal 15 detik.

\section{Hasil dan Pembahasan}

\subsection{Preparasi dan Aktivasi Lempung}

Lempung alam yang diperoleh terlebih dahulu dilakukan fraksinasi dengan akuades. Fraksinasi dilakukan berdasarkan perbedaan densitas, di mana fraksi ringan untuk mengendap butuh waktu lebih lama karena adanya interaksi yang terjadi antara lapisan silikat pada lempung dengan molekul air lebih kuat. Pengotor/fraksi berat memiliki densitas yang lebih besar seperti kalsit, kuarsa, klinoptilolit dan feldspar akan mengendap lebih cepat. Fraksi ringan dan berat yang telah didapatkan dari hasil fraksinasi disaring lalu dikeringkan dalam oven $110^{\circ} \mathrm{C}$ selama 2 jam. Selanjutnya, masing-masing fraksi ditumbuk dan diayak dengan ayakan 170 mesh yang bertujuan untuk memisahkan fraksi undersize (fraksi yang lolos ayakan) dengan fraksi yang oversize (fraksi yang tertahan pada ayakan).

Proses aktivasi lempung pada penelitian ini dengan cara aktivasi kimia yaitu menambahkan $\mathrm{HCl}$ ke dalam lempung yang bertujuan untuk menghilangkan senyawa pengotor yang dapat larut dalam HCl. Selain itu, peran aktivasi adalah untuk menyeragamkan kation, kation-kation pada lempung seperti $\mathrm{K}^{+}, \mathrm{Na}^{+}, \mathrm{Ca}^{2+}, \mathrm{Mg}^{2+}, \mathrm{Fe}^{2+}$ diganti dengan ion $\mathrm{H}^{+}$, sehingga diharapkan diperoleh lempung yang homoionik [8].

\subsection{Pemilaran Lempung}

Tahap pembuatan agen pemilar yaitu tahap pembuatan polioksokation $\mathrm{Al} / \mathrm{Cr}$ sebagai agen pemilar ke dalam ruang antar lapis lempung. Agen pemilar lempung merupakan campuran larutan $\mathrm{NaOH}$ dengan larutan senyawa kompleks $\mathrm{AlCl}_{3} .6 \mathrm{H}_{2} \mathrm{O}$ dan larutan $\mathrm{CrCl}_{3} .6 \mathrm{H}_{2} \mathrm{O}$ dengan perbandingan agen pilar $\mathrm{Al} 25 \%$ dan $\mathrm{Cr} 75 \%$ dan perbandingan mol $\mathrm{OH}: \mathrm{Al}$ atau $\mathrm{OH}$ : $\mathrm{Cr}$ adalah 2 mol, hal ini bertujuan untuk mengontrol $\mathrm{pH}$ larutan campuran, sehingga terjadi reaksi maksimum antara ion-ion $\mathrm{Al}^{3+}$ dan $\mathrm{Cr}^{3+}$ dengan $\mathrm{OH}$. Keasaman atau $\mathrm{pH}$ larutan $\mathrm{AlCl}_{3} .6 \mathrm{H}_{2} \mathrm{O}$ awal terukur 3, setelah penambahan larutan $\mathrm{NaOH}, \mathrm{pH}$ larutan menjadi 4, hal ini sesuai karena pada $\mathrm{pH}$ 4 terbentuk ion Keggin $=\mathrm{Al}_{13}$ [9], sedangkan $\mathrm{pH}$ larutan $\mathrm{CrCl}_{3} \cdot 6 \mathrm{H}_{2} \mathrm{O}$ awal terukur 4. Setelah penambahan larutan $\mathrm{NaOH}, \mathrm{pH}$ larutan menjadi 5 , hal ini sesuai dengan penelitian yang dilakukan oleh Mokrousova [10], bahwa kondisi optimal untuk memodifikasi lempung terpilar Cr(III) yaitu pada rentang $\mathrm{pH}$ 4-6.

Tahap interkalasi adalah tahap dimana agen pemilar dimasukkan ke dalam antar lapis silikat lempung alam dengan cara mencampurkan senyawa komples Al/Cr-polihidroksi dengan lempung alam dalam air bebas ion. Lempung hasil interkalasi dicuci beberapa kali dengan air bebas ion dengan menghilangkan ion $\mathrm{Cl}^{-}$(sisa $\mathrm{HCl}$ dari hasil reaksi). Lempung harus bersih dari ion $\mathrm{Cl}^{-}$ agar tidak mengganggu struktur lempung ketika proses kalsinasi [11].

\subsection{Karakterisasi Basal Spacing Lempung}

Hasil pilarisasi dianalisis menggunakan XRD yang diamati dengan adanya pergeseran puncak pada bidang do01 (basal spacing), selain itu dari hasil analisis XRD juga dapat diketahui unsur mineral apa saja yang terdapat dalam bentonit. Difraktogram lempung terpilar fraksi berat disajikan pada gambar 1. Hasil difraktogram menunjukkan adanya puncak $2 \theta=5,76^{\circ}$ pada $\mathrm{LB}$ yang merupakan ciri mineral montmorillonite. Puncak yang tajam ditunjukkan pada daerah $2 \theta=$ $26,6^{\circ}$ yang menjadi ciri khas mineral kuarsa menurut rruf.info. Difraktogram lempung terpilar fraksi ringan disajikan pada gambar 2 . Berdasarkan hasil difraktogram terlihat perbedaan dari fraksi ringan teraktivasi dengan fraksi ringan terpilar di daerah $2 \theta<10^{\circ}$. Terdapat puncak $2 \theta=$ $5,68^{\circ}$ di LR yang merupakan ciri mineral montmorillonite.

Refleksi puncak yang khas untuk montmorillonit adalah ramping. Namun dari hasil difraktogram kedua fraksi puncak montmorillonit melebar dan intensitasnya lemah. Hal ini mengindikasikan kandungan montmorillonit yang sangat rendah dalam lempung, disamping juga akibat kerusakan struktur montmorillonit akibat proses kalsinasi [12]. Adanya puncak $2 \theta$ tersebut menunjukkan adanya mineral kuarsa yang menjadi mineral penyusun pada fraksi ringan dan fraksi berat lempung terpilar. Hal ini mengindikasikan bahwa lempung alam boyolali tidak murni dan masih tercampur dengan mineral kuarsa. Dari proses faksinasi yang telah dilakukan dapat disimpulkan bahwa belum menghasilkan lempung montmorilonit yang sempurna. 


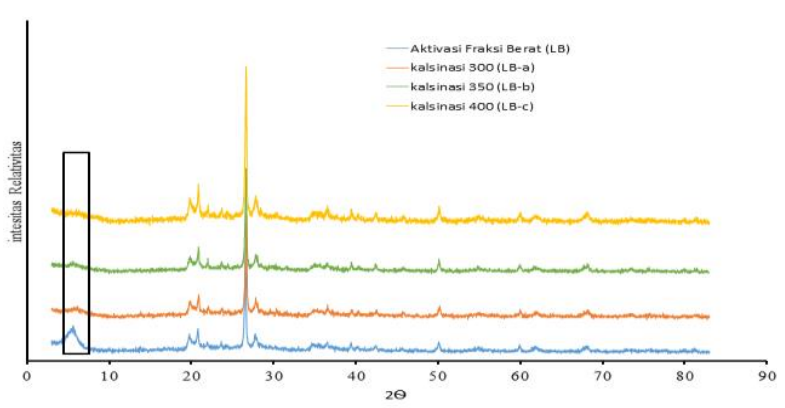

Gambar 1. Difraktogram fraksi berat lempung terpilar $\mathrm{Al} / \mathrm{Cr}$ dengan variasi suhu kalsinasi

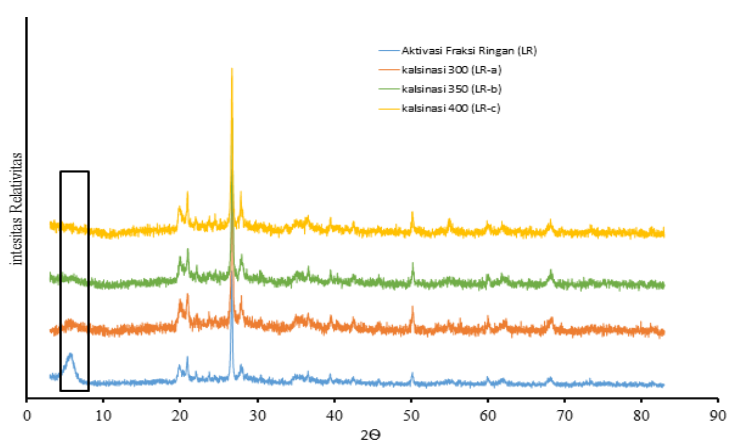

Gambar 2. Difraktogram fraksi ringan lempung terpilar $\mathrm{Al} / \mathrm{Cr}$ dengan variasi suhu kalsinasi

Keberhasilan pilarisasi $\mathrm{Al} / \mathrm{Cr}$ dapat diamati dari adanya pergeseran puncak pada $2 \theta$ (basal spacing). Nilai basal spacing hasil XRD disajikan pada Tabel 1.

Tabel 1. Nilai basal spacing dari masingmasing fraksi ringan dan berat

\begin{tabular}{ccc}
\hline Sampel & $2 \theta$ & basal spacing \\
\hline LB & 5,76 & 15,32 \\
LB-a & 5,87 & 15,04 \\
LB-b & 5,74 & 15,37 \\
LB-c & 5,58 & 15,82 \\
LR & 5,68 & 15,54 \\
LR-a & 5,61 & 15,72 \\
LR-b & 5,56 & 15,88 \\
LR-c & 5,52 & 15,99 \\
\hline
\end{tabular}

Berdasarkan hasil pada Tabel 1 terlihat adanya peningkatan basal spacing pada fraksi berat dan fraksi ringan yang terkalsinasi. Peningkatan basal spacing pada fraksi ringan dan berat terpilar karena telah terjadi pemasukan $\mathrm{Al} / \mathrm{Cr}$ yang memiliki ukuran yang besar ke dalam antar lapis lempung sehingga mengakibatkan basal spacing lempung meningkat dan mengindikasikan bahwa proses pemilaran berhasil. Besarnya peningkatan basal spacing ditentukan oleh adanya oksida $\mathrm{Al}\left(\mathrm{Al}_{2} \mathrm{O}_{3}\right)$ dan $\mathrm{Cr}$ $\left(\mathrm{Cr}_{2} \mathrm{O}_{3}\right)$ dan menunjukkan pula bahwa terjadi cation exchange di mana kation antar lapis lempung tergantikan menjadi Al/Cr oksida [13].
Penurunan nilai basal spacing LB terhadap LBa kemungkinan disebabkan karena kerapatan partikel lebih besar, sehingga suhunya belum mencukupi untuk kalsinasi secara sempurna. Stabilitas lempung terpilar $\mathrm{Al} / \mathrm{Cr}$ yang terbentuk bisa bertahan hingga suhu $400^{\circ} \mathrm{C}$, sehingga memberikan basal spacing yang besar.

\subsection{Adsorpsi Minyak Sisa Pakai}

Tujuan dari adsorpsi ini adalah untuk mendapatkan suhu kalsinasi terbaik dilihat dari daya serap terbesar yang akan digunakan dalam proses adsorpsi selanjutnya yaitu untuk uji kualitas minyak. Pengukuran nilai absorbansi filtrat hasil adsorpsi lempung terpilar pada minyak sisa pakai diukur menggunakan spektrofotometer UV-Vis pada $\lambda 430 \mathrm{~nm}$. Datan hasil adsorpsi minyak sisa pakai disajikan pada Tabel 2.

Tabel 2. Hasil proses adsorpsi pada lempung terpilar fraksi ringan dan fraksi berat

\begin{tabular}{|c|c|c|c|c|c|}
\hline \multirow{3}{*}{ Sampel } & \multicolumn{3}{|c|}{$\begin{array}{c}\text { Absorbansi Filtrat Minyak Sisa } \\
\text { Pakai }\end{array}$} & \multirow{2}{*}{\multicolumn{2}{|c|}{ Daya Adsorpsi (\%) }} \\
\hline & \multirow{2}{*}{$\begin{array}{c}\text { Sebelum } \\
\text { Adsorpsi (A) }\end{array}$} & \multicolumn{2}{|c|}{$\begin{array}{l}\text { Setelah Adsorpsi } \\
\text { (A) }\end{array}$} & & \\
\hline & & $\begin{array}{c}\text { Fraksi } \\
\text { Berat }\end{array}$ & $\begin{array}{l}\text { Fraksi } \\
\text { Ringan }\end{array}$ & $\begin{array}{c}\text { Fraksi } \\
\text { Berat }\end{array}$ & $\begin{array}{l}\text { Fraksi } \\
\text { Ringan }\end{array}$ \\
\hline $\begin{array}{l}\text { Lempung } \\
\text { teraktivasi }\end{array}$ & \multirow{4}{*}{2,945} & 2,885 & 2,880 & 2,03 & 2,21 \\
\hline $\begin{array}{l}\text { Lempung terpilar } \\
\text { suhu } 300^{\circ} \mathrm{C}\end{array}$ & & 2,875 & 2,815 & 2,54 & 4,41 \\
\hline $\begin{array}{l}\text { Lempung terpilar } \\
\text { suhu } 350^{\circ} \mathrm{C}\end{array}$ & & 2,705 & 2,835 & 8,14 & 3,73 \\
\hline $\begin{array}{l}\text { Lempung terpilar } \\
\text { suhu } 400^{\circ} \mathrm{C}\end{array}$ & & 2,675 & 2,760 & 9,16 & 6,28 \\
\hline
\end{tabular}

Berdasarkan Tabel 2, daya adsorpsi lempung teraktivasi ke lempung terpilar mengalami peningkatan dari masing-masing fraksi. Daya adsorpsi terbaik fraksi ringan dan fraksi berat pada suhu $400^{\circ} \mathrm{C}$ dengan persentase daya adsorpsi 6,28\% (fraksi ringan) dan 9,16\% (fraksi berat). Penurunan nilai absorbansi diduga karena meningkatnya nilai basal spacing pada suhu kalsinasi lempung terpilar $400^{\circ} \mathrm{C}$. Sehingga, dapat disimpulkan bahwa suhu kalsinasi $400^{\circ} \mathrm{C}$ bukan merupakan suhu optimum lempung terpilar $\mathrm{Al} / \mathrm{Cr}$ tetapi kemampuan adsorpsi pada suhu kalsinasi $400^{\circ} \mathrm{C}$ mengalami peningkatan yang paling besar.

\subsection{Kualitas Minyak}

Sampel minyak yang digunakan adalah minyak jelantah (minyak goreng sisa pakai) dan adsorben yang digunakan adalah lempung terpilar $\mathrm{Al} / \mathrm{Cr}$ dengan suhu kalsinasi $400^{\circ} \mathrm{C}$ 


\subsubsection{Penentuan Bilangan Asam}

Nilai bilangan asam minyak sisa pakai setelah adsorpsi dibandingkan dengan standar mutu minyak goreng SNI 01-3741-2013 yaitu maksimal 0,6 mg KOH/g. Hasil bilangan asam pada minyak sisa pakai disajikan pada Gambar 3.

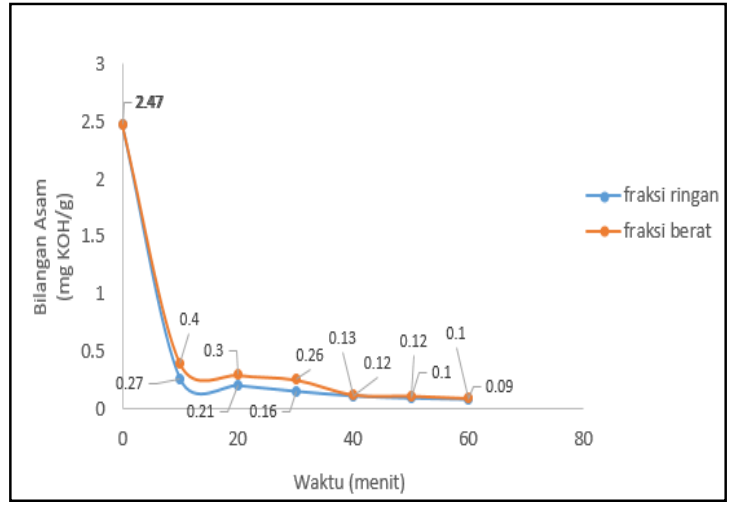

Gambar 3. Grafik hubungan antara bilangan asam minyak sisa pakai dengan variasi waktu kontak

Berdasarkan Gambar 3 terlihat bahwa bilangan asam mengalami penurunan seiring bertambah waktu kontak adsorpsi. Sebelum adsorpsi, bilangan asam dalam minyak sisa pakai yaitu 2,47 $\mathrm{mg} \mathrm{KOH} / \mathrm{g}$ yang dimana tidak sesuai dengan SNI 01-3741-2013 maksimal 0,6 $\mathrm{mg} \mathrm{KOH} / \mathrm{g}$. Menurut Sudarmadji dkk [14] semakin besar angka ini berarti kandungan asam lemak bebas semakin tinggi, sementara asam lemak bebas yang terkandung dalam sampel dapat berasal dari proses hidrolisis ataupun karena proses pengolahan yang kurang baik. Makin tinggi bilangan asam maka makin rendah kualitasnya. Minyak sisa pakai yang telah diadsorpsi oleh lempung terpilar $\mathrm{Al} / \mathrm{Cr}$ fraksi ringan dan fraksi berat mengalami penurunan bilangan asam yang signifikan di setiap variasi waktu kontak, lempung terpilar $\mathrm{Al} / \mathrm{Cr}$ mampu menurunkan bilangan asam dan semakin lama waktu kontak adsorpsi, maka penurunan bilangan asam semakin meningkat.

\subsubsection{Penentuan Bilangan Peroksida}

Nilai bilangan peroksida minyak sisa pakai setelah adsorpsi dibandingkan dengan standar mutu minyak goreng SNI 01-3741-2013 yaitu maksimal 10 mek $\mathrm{O}_{2} / \mathrm{kg}$. Hasil bilangan peroksida pada minyak sisa pakai disajikan pada Gambar 4.

Berdasarkan hasil Gambar 4 menunjukkan bahwa bilangan peroksida mengalami penurunan seiring bertambah waktu kontak adsorpsi. Sebelum adsorpsi, bilangan peroksida pada minyak sisa pakai yaitu 57,5 mek $\mathrm{O}_{2} / \mathrm{kg}$ yang dimana tidak sesuai dengan SNI 01-37412013 maksimal 10 mek $\mathrm{O}_{2} / \mathrm{kg}$. Bilangan peroksida yang tinggi mengindikasikan lemak atau minyak sudah teroksidasi (Aminah dan Isworo, 2010). Minyak sisa pakai yang telah diadsorpsi oleh lempung terpilar $\mathrm{Al} / \mathrm{Cr}$ fraksi ringan dan fraksi berat mengalami penurunan bilangan peroksida mencapai angka batas aman kandungan peroksida yang diizinkan sesuai dengan SNI 01-3741-2013, sehingga, semakin lama waktu kontak adsorpsi maka kemampuan menurunkan bilangan peroksida makin besar.

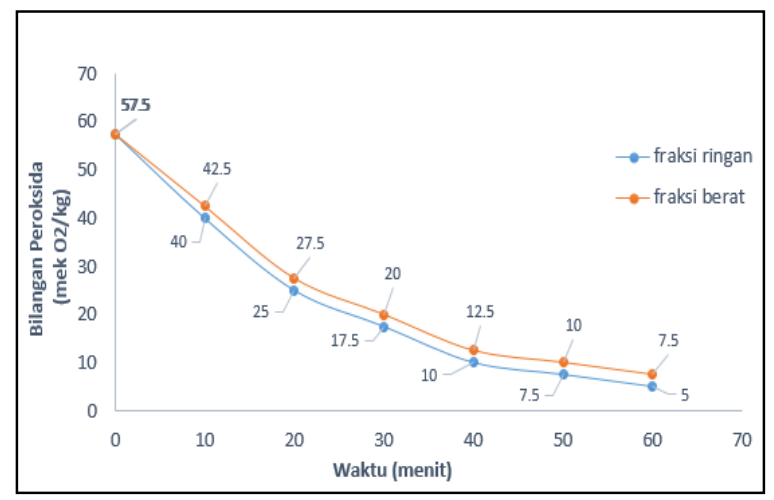

Gambar 4. Grafik hubungan antara bilangan peroksida minyak sisa pakai dengan variasi waktu kontak

\section{Kesimpulan}

Telah diperoleh lempung terpilar $\mathrm{Al} / \mathrm{Cr}$. Pemilaran lempung dapat meningkatkan basal spacing. Basal spacing yang terbesar dicapai pada suhu kalsinasi $400^{\circ} \mathrm{C}$ yaitu fraksi ringan $18,84 \AA$ dan fraksi berat 16,53 Å. Kemampuan lempung terpilar $\mathrm{Al} / \mathrm{Cr}$ untuk adsorpsi minyak sisa pakai memiliki daya serap besar pada suhu kalsinasi $400^{\circ} \mathrm{C}$ yaitu pada fraksi berat $9,16 \%$ dan fraksi ringan 6,28 \%.

Adsorben untuk waktu adsorpsi yang sama yaitu fraksi ringan mempunyai kemampuan menurunkan bilangan asam dan bilangan peroksida lebih besar di banding fraksi berat. Minyak sisa pakai mencapai batas aman bilangan asam pada waktu adsorpsi 10 menit untuk masing-masing fraksi, sedangkan bilangan peroksida pada waktu adsorpsi 40 menit untuk fraksi ringan dan 50 menit untuk fraksi berat.

\section{Daftar Pustaka}

[1] Kusumastuti, Kinerja Zeolit Dalam Memperbaiki Mutu Minyak Goreng, Jurnal Teknologi dan Industri Pangan, 15, 2, (2004), 141-144. 
[2] Yuliana, Y., J. S. Veronica, Bambang Gunantara, Penggunaan Adsorben untuk Mengurangi Kadar Free Fatty Acid, Peroxide Value dan Warna Minyak Goreng Bekas, Jurnal Teknik Kimia Indonesia, 4, 2, (2018), 212-218

http://dx.doi.org/10.5614/jtki.2005.4.2.4

[3] Boki, Keito, Moriaki Kubo, Tetsuyuki Wada, Takamichi Tamura, Bleaching of AlkaliRefined Vegetable Oils with Clay Minerals, Journal of the American Oil Chemists Society, 69, 3, (1992), 232-236 https://doi.org/10.1007/BF02635892

[4] Mukasa-Tebandeke, I. Z., P. J. M. Ssebuwufu, S. A. Nyanzi, G. W. Nyakairu, M. Ntale, F. Lugolobi, Andreas Schumann, Adsorption Behavior of Acid-Leached Clays in Bleaching of Oil, American Journal of Analytical Chemistry, 06, 06, (2015), 495512

https://doi.org/10.4236/ajac.2015.66049

[5] Sianturi, Delfa Bahari, Pengaruh Suhu, Waktu, dan Jumlah Adsorben Bentonit yang Diaktivasi dengan HCL Terhadap Daya Jerap Karoten dan Asam Lemak Bebas dari Crude Palm Oil, (2020).

[6] Pergher, Sibele Berenice Castellã, Renato Sprung, Pillarization of A Brazilian Clay with Aluminium Polyhydroxications: Preparation, Characterization and Catalytic Properties, Química Nova, 28, 5, (2005), 777-782 https://doi.org/10.1590/S010040422005000500008

[7] Ding, Menglin, Shufeng Zuo, Chenze Qi, Preparation and Characterization of Novel Composite AlCr-Pillared Clays and Preliminary Investigation for Benzene Adsorption, Applied Clay Science, 115, (2015),9-16

https://doi.org/10.1016/j.clay.2015.07.02 $\underline{0}$

[8] Hymore, FK, Effects of Some Additives on The Performance of Acid-Activated Clays in The Bleaching of Palm Oil, Applied clay science, 10, 5, (1996), 379-385 https://doi.org/10.1016/01691317(95)00034-8

[9] Moore, Lesley E. Smart Elaine A., Solid State Chemistry, Third ed., CRC Press
Taylor \& Francis Group, United States, 2005,

[10] Moraru, O Mokrousova V, The Effect of Montmorillonite Modification by $\mathrm{Cr}(\mathrm{III})$ Compounds on Its Microcrystalline Structure and Electrosurface Properties Scientific Annals, School of Geology, Aristotle University of Thessaloniki Proceedings of the XIX CBGA Congress, Thessaloniki, Greece, 99, (2010), 281-287

[11] Darmawan, Adi, Ahmad Suseno, Slamet Agus Purnomo, Sintesis Lempung Terpilar Titania, Jurnal Kimia Sains Dan Aplikasi, 8, 3,(2005),61-68 https://doi.org/10.14710/iksa.8.3.61-68

[12] Widihati, Ida Ayu Gede, Sintesis Lempung Montmorillonit Terpilar $\mathrm{Fe}_{2} \mathrm{O}_{3}$ dan Kajian Sifat-Sifat Fisiknya, [Yogyakarta]: Universitas Gadjah Mada, 2002.

[13] Li, Yuan, Xiaojiao Cai, Jingwei Guo, Shimin Zhou, Ping $\mathrm{Na}, \mathrm{Fe} / \mathrm{Ti}$ Co-Pillared Clay for Enhanced Arsenite Removal and Photo Oxidation Under UV Irradiation, Applied Surface Science, 324, (2015), 179-187 https://doi.org/10.1016/j.apsusc.2014.10 .111

[14] Sudarmaji, Slamet, Bambang Haryono, Suhardi, Prosedur analisa untuk bahan makanan dan pertanian, liberty, 1984. 